\title{
Disease Incidence-Inoculum Dose Relationships for Botrytis cinerea and Penicillium expansum and Decay of Pear Fruit Using Dry, Airborne Conidia
}

\author{
Robert A. Spotts and Louis A. Cervantes, Oregon State University Mid-Columbia Agricultural Research and Ex- \\ tension Center, 3005 Experiment Station Drive, Hood River 97031
}

\begin{abstract}
Spotts, R. A., and Cervantes, L. A. 2001. Disease incidence-inoculum dose relationships for Botrytis cinerea and Penicillium expansum and decay of pear fruit using dry, airborne conidia. Plant Dis. 85:755-759.

The objective of this research was to determine quantitative relationships between incidence of pear fruit decay and inoculum dose of Botrytis cinerea and Penicillium expansum using dry conidia applied to wet or dry pears in a settling tower. On wet fruit, incidence of gray mold fruit rot increased from 0.1 to $83.1 \%$ as the airborne concentration of $B$. cinerea conidia increased from 0 to 8.6 spores per liter of air. Significantly less decay occurred in fruit inoculated dry compared to wet, particularly in fruit wounded after inoculation. Incidence of blue mold increased from 1 to $100 \%$ as the airborne concentration of $P$. expansum conidia increased from 0.1 to 803.5 spores per liter of air. Blue mold incidence was not affected by fruit wetness or time of wounding relative to inoculation. All regressions of decay incidence versus airborne and surface conidial concentrations were highly significant $(P=0.01)$.
\end{abstract}

The two most important postharvest storage decays of apple and pear fruit are gray mold and blue mold caused by Botrytis cinerea Pers.:Fr. and Penicillium expansum Link, respectively $(11,13)$. Both fungi colonize litter on the orchard floor (6). Conidia can become airborne and contaminate the surfaces of fruit and bins during harvest $(9,13,17)$. Infection of fruit occurs when spores enter wounds or infect through the abscission zone of the pedicel (stem) $(4,14,15)$. This may occur during harvest or later, as fruit float through contaminated dump tank or flume water in the packinghouse (16).

The relationship between incidence of pear fruit decay (DI) and inoculum dose (ID) has been determined for conidia of $B$. cinerea and $P$. expansum in water suspensions (15) but not for conidia in air. Salinas et al. (12) designed a settling tower for inoculation of gerbera flowers with dry conidia of B. cinerea. Coertze and Holz (5) used the tower inoculation technique to study surface colonization, penetration, and lesion formation on grapes inoculated with airborne conidia of $B$. cinerea. Spotts and Holz (19) used a settling tower to inoculate grape and plum with dry conidia of $B$. cinerea and to study conidial adhesion and removal. None of these studies included determination of the DI:ID relationships for B. cinerea. Similarly, DI:ID relation-

Corresponding author: R. A. Spotts

E-mail: Robert.spotts@orst.edu

Accepted for publication 31 March 2001.

Publication no. D-2001-0514-01R

(C) 2001 The American Phytopathological Society ships for conidia of $P$. expansum on pear fruit have not been investigated.

The objective of this research was to determine quantitative relationships between incidence of gray mold and blue mold of pear fruit and inoculum dose using dry conidia applied in a settling tower. Fruit were puncture-wounded before and after inoculation to simulate variation in time of wounding during harvest in relation to arrival of inoculum at the infection court. Because fruit surfaces in an orchard at harvest can be dry or wet with rain or dew, inoculation of both wet and dry fruit was included in this study.

\section{MATERIALS AND METHODS}

Fruit. D'Anjou pear fruit were harvested at commercial maturity with flesh firmness of 67 newtons at the MidColumbia Agricultural Research and Extension Center (MCAREC), Hood River. Fruit were stored until needed in air at $-1.1^{\circ} \mathrm{C}$ in cardboard fruit boxes lined with perforated polyethylene bags. Fruit surfaces were disinfested with $100 \mu \mathrm{g}$ sodium hypochlorite per milliliter of water for 2 min and rinsed with tap water before inoculation. For experiments with dry fruit, disinfested fruit were placed in sterile trays and dried overnight at $20^{\circ} \mathrm{C}$ in a room cleaned previously with $5.25 \mathrm{~g}$ sodium hypochlorite per liter of water. Inoculation was done at $15^{\circ} \mathrm{C}$ to prevent moisture from condensing on the fruit surface. For experiments with wet fruit, fruit were removed from $-1.1^{\circ} \mathrm{C}$, disinfested, then inoculated immediately at $15^{\circ} \mathrm{C}$. Thus surfaces were wet from both the water rinse and water condensing on the cold surface.

Inoculum. $B$. cinerea isolate 62 , obtained from an infected d'Anjou pear fruit in 1982, was cultured on potato dextrose agar acidified with $1.5 \mathrm{ml}$ of $85 \%$ lactic acid per liter (APDA) to prevent bacterial contamination. Conidia were harvested dry from 14-day-old cultures with a cyclone surface sampler (Burkard Manufacturing Co. Ltd., Rickmansworth, Hertfordshire, United Kingdom). Dry conidia were diluted 1:9 and 1:99 with talc (T-2015, Sigma Chemical Co., St. Louis, MO) that was sterilized at $140^{\circ} \mathrm{C}$ for $4 \mathrm{~h}$. The conidia/talc powder was mixed for $15 \mathrm{~h}$ in a twin shell blender (model SB-8, PattersonKelly Co., E. Stroudsburg, PA). The conidia/talc powder was stored at $3^{\circ} \mathrm{C}$ and used as inoculum over a 6-week period. Germination of conidia in the powder was determined prior to each experiment by mixing with sterile distilled water, placing drops on APDA, and observing germination of 100 conidia microscopically at $\times 250$ after $24 \mathrm{~h}$ at $20^{\circ} \mathrm{C}$. Germination was between 95 and $100 \%$ for all experiments.

$P$. expansum isolate 46 , obtained from an infected d'Anjou pear fruit in 1980, was cultured on APDA and spores harvested from 20-day-old cultures as described above. Conidia were mixed with talc and stored until use as described above. Germination of conidia of $P$. expansum in the talc powder was 96 to $100 \%$ during the 2 months it took to complete the inoculation experiments.

Inoculation. Pear fruit were inoculated in an aluminum tower $2.06 \mathrm{~m}$ height $\times 0.68$ $\mathrm{m} \times 0.68 \mathrm{~m}$. Prior to each experiment, the room floor was sprayed with $5.25 \mathrm{~g}$ sodium hypochlorite per liter of water, and the room air was sprayed with Lysol (0.1 $\%$ alkyl dimethyl benzyl ammonium saccharinate plus $79 \%$ ethanol); (L \& F Products, Montvale, NJ). The inside of the tower was sterilized with $95 \%$ ethanol. After each inoculation, air was exhausted from the tower for $2 \mathrm{~min}$ with a blower vented outside the building.

Fruit were placed in the bottom of the tower in two cardboard trays, 22 fruit per tray. Fruit in one of the trays were wounded $(6 \mathrm{~mm}$ diameter $\times 3 \mathrm{~mm}$ deep, two wounds per fruit) with a sterile metal tool. Conidia/talc mixtures ranging from 1.0 to $5.0 \mathrm{mg}$ of the $1: 99$ dilution and 0.5 to $5.0 \mathrm{mg}$ of the $1: 9$ dilution were used to obtain inoculum ranging from 0.01 to 0.5 $\mathrm{mg}$ of conidia. Each mixture was weighed, transferred to a sterile glass tube of $6 \mathrm{~mm}$ internal diameter, and forcefully blown into the top center of the tower with 12 squeezes of an aspirator bulb. Spores were 
allowed to settle for $20 \mathrm{~min}$, and then fruit were removed. Nonwounded fruit were punctured as described above, and all fruit were placed in a cardboard fruit box lined with a perforated polyethylene bag. After 7 days incubation at $20^{\circ} \mathrm{C}$, infection at wounds was determined visually and incidence of decay was calculated.

Density of conidia of $B$. cinerea settling onto surfaces was determined by placing three $2.54 \times 7.62 \mathrm{~cm}$ glass microscope slides coated with a thin layer of silicone grease at different locations on the trays.
At the end of an inoculation, slides were removed, stained with cotton blue in lactophenol, and conidia in 20 to 40 microscope fields counted at $\times 250$. Density of spores of $P$. expansum on the surface was determined by placing three $100 \times 15 \mathrm{~mm}$ petri dishes containing APDA on the trays. After exposure, plates were incubated at $22^{\circ} \mathrm{C}$ for 3 to 4 days and colonies counted with the aid of a stereomicroscope at $\times 15$.

Density of conidia of $B$. cinerea and $P$. expansum in the air inside the tower was determined by sampling with a portable air
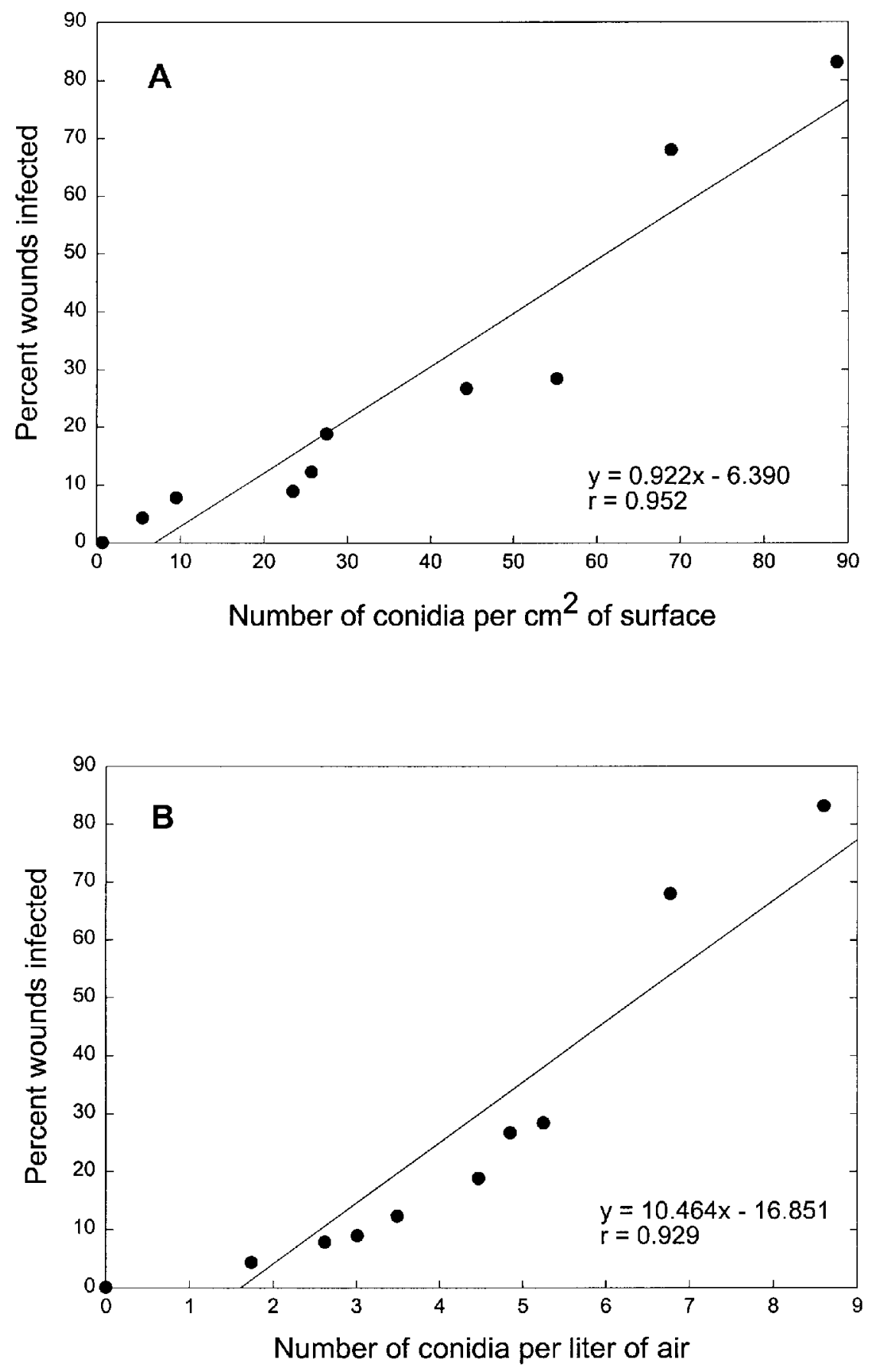

Fig. 1. Relationship between incidence of gray mold of d'Anjou pear fruit and inoculum dose of Botrytis cinerea expressed as $\mathbf{A}$, conidia per $\mathrm{cm}^{2}$ and $\mathbf{B}$, number of conidia per liter of air. Fruit were wet when inoculated. Data were combined for fruit wounded before and after inoculation.

sampler for agar plates (Burkard Manufacturing Co. Ltd.). The manufacturer rates impaction efficiency of this sampler at $100 \%$ for $5 \mu \mathrm{m}$ particles at the 20-litersper-min sampling rate used here. Air was sampled through a port on the side of the tower $15 \mathrm{~cm}$ above the bottom. For 1:99 mixtures, air was sampled onto the same APDA plate for $15 \mathrm{~s}$ at $5,10,15$, and 19 min after inoculation for a total sample volume of 20 liters. For 1:9 mixtures, the sampling time was $5 \mathrm{~s}$, giving a total sample volume of 6.67 liters. Plates were incubated at $22^{\circ} \mathrm{C}$ and colonies counted after 2 to 4 days.

Statistics. Each inoculum concentration was replicated three times per experiment for each fungus. Each complete experiment, which included all concentrations of inoculum, was done twice with wet fruit and twice with dry fruit for each fungus. The relationships between decay incidence and inoculum dose, expressed as both conidia per $\mathrm{cm}^{2}$ of surface and conidia per liter of air were plotted and subjected to linear regression analysis. The SAS GLM analysis of variance procedure (SAS Institute, Cary, NC) was used to determine significance among regressions related to experiment, time of wounding, and wet versus dry fruit.

\section{RESULTS}

No significant differences were found between repeated experiments with either $B$. cinerea or $P$. expansum in the number of conidia per $\mathrm{cm}^{2}$, number of conidia per liter of air, or decay incidence. Thus, data from each of the two complete experiments with wet fruit and each of the two experiments done with dry fruit were combined for each fungus.

B. cinerea. Using a range of inoculum concentrations from 0.01 to $0.50 \mathrm{mg}$ of conidia of $B$. cinerea, the number of conidia ranged from 3.1 to 94.7 per $\mathrm{cm}^{2}$ on the slide surface and from 1.7 to 8.6 per liter of air, respectively. Background concentrations when no inoculum was introduced into the tower were 1.3 conidia per $\mathrm{cm}^{2}$ and 0.0 per liter of air.

Decay incidence of wet fruit ranged from $0.1 \%$ in the control to $83.1 \%$ in fruit inoculated with $0.5 \mathrm{mg}$ of conidia. The linear regression equations for decay incidence plotted against conidia per $\mathrm{cm}^{2}$ and against conidia per liter of air were highly significant $(P=0.01)$ with correlation coefficients $(r)$ of 0.952 and 0.929 , respectively (Fig. 1A and 1B). Decay incidence of wet fruit was not affected by time of wounding relative to inoculation.

Overall decay incidence of dry fruit was significantly less $(P=0.004)$ than that of wet fruit and also was affected by time of wounding relative to inoculation $(P=$ $0.05)$. For fruit wounded before inoculation, decay incidence ranged from 0.2 to $65.1 \%$. For fruit wounded after inoculation, decay incidence ranged from 0.4 to 
$45.5 \%$. Regression of decay incidence versus conidia per $\mathrm{cm}^{2}$ and per liter was highly significant $(P=0.01)$ with all correlation coefficients $(r)$ above 0.93 (Fig. 2A and 2B).

P. expansum. Using a range of inoculum concentrations from 0.01 to $0.50 \mathrm{mg}$ of conidia of $P$. expansum, the number of cfu per $\mathrm{cm}^{2}$ on the petri dish surface ranged from 7.2 to 457.1 and from 13.7 to 803.5 per liter of air, respectively. Background concentrations when no inoculum was introduced into the tower were 0.0 conidia per $\mathrm{cm}^{2}$ and 0.1 per liter of air.

Overall decay incidence of fruit was not significantly affected by time of wounding relative to inoculation. Similarly, fruit inoculated wet showed no significant difference from fruit inoculated dry. Decay incidence ranged from 1 to $100 \%$. Regression of decay incidence versus conidia per $\mathrm{cm}^{2}$ and per liter was highly significant $(P$ $=0.01)$ with correlation coefficients $(r)$ above 0.98 (Fig. 3).

\section{DISCUSSION}

A wide range of airborne conidial concentrations of $B$. cinerea and $P$. expansum occur in pome fruit orchards and packinghouses in the Pacific Northwest. Concentrations of $B$. cinerea up to 3.1 conidia per liter of air were measured in orchards between 1996 and 1999 (R. Spotts, unpublished data). In this limited sampling, air was not sampled in the vicinity of cull bins containing decayed fruit where levels of $B$. cinerea may be higher than previously measured. Previous reports found airborne concentrations of $B$. cinerea that ranged from 0.11 conidia per liter in strawberry fields (10) to 3.0 conidia per liter in raspberry fields (8). Concentrations used herein ranged from 0.0 to 8.6 per liter. We did not find any previous reports concerning levels of $P$. expansum in air, but in preliminary samples, we found concentrations ranging from 0 to 1020 conidia per liter in packinghouses in the Mid-Columbia area of Oregon and Washington (R. Spotts, unpublished data). Levels of $P$. expansum can exceed 100 conidia per liter in air samples taken in North Central Washington (P. Sanderson, unpublished data). Two previous studies $(3,16)$ included data on airborne $P$. expansum conidia, but conidia were collected by passive settling onto media in petri dishes. Thus, values are not comparable with the present study, in which air was impinged onto the dishes. The $B$. cinerea and P. expansum conidial concentrations used herein are representative of those occurring in the field and orchard in a variety of cropping systems. In addition, these conidial concentrations resulted in a wide range of incidence of decay.

Wounds made during harvest are the primary sites of infection of pear fruit (14). In a 4-year study, an average of $2.9 \%$ of d'Anjou and 4.3 to $13.9 \%$ of Bosc pear fruit were wounded during harvest and handling (20). Because conidia probably are being deposited on the fruit surface constantly during harvest, wounding will drive previously deposited conidia into the flesh and also provide an entry for conidia that arrive after wounding occurs. We attempted to simulate both situations in this study by wounding some fruit before inoculation and other fruit after inoculation. Wounding dry fruit before inoculation resulted in a higher incidence of infection with $B$. cinerea than when wounding was done after inoculation. However, P. expansum infection of wet or dry fruit was not affected by time of wounding. Conidia of $B$. cinerea adhere to tomato fruit cuticle, grape berry epidermis, and leaves and petals of other hosts immediately upon hydration (7). Conidia of $B$. cinerea adhere more strongly when applied in a water suspension or to the wet surface of grape fruit than when dry conidia are applied to a dry surface (19). However, adhesion of conidia of $P$. expansum is not improved by hydration (19). The wounding process releases
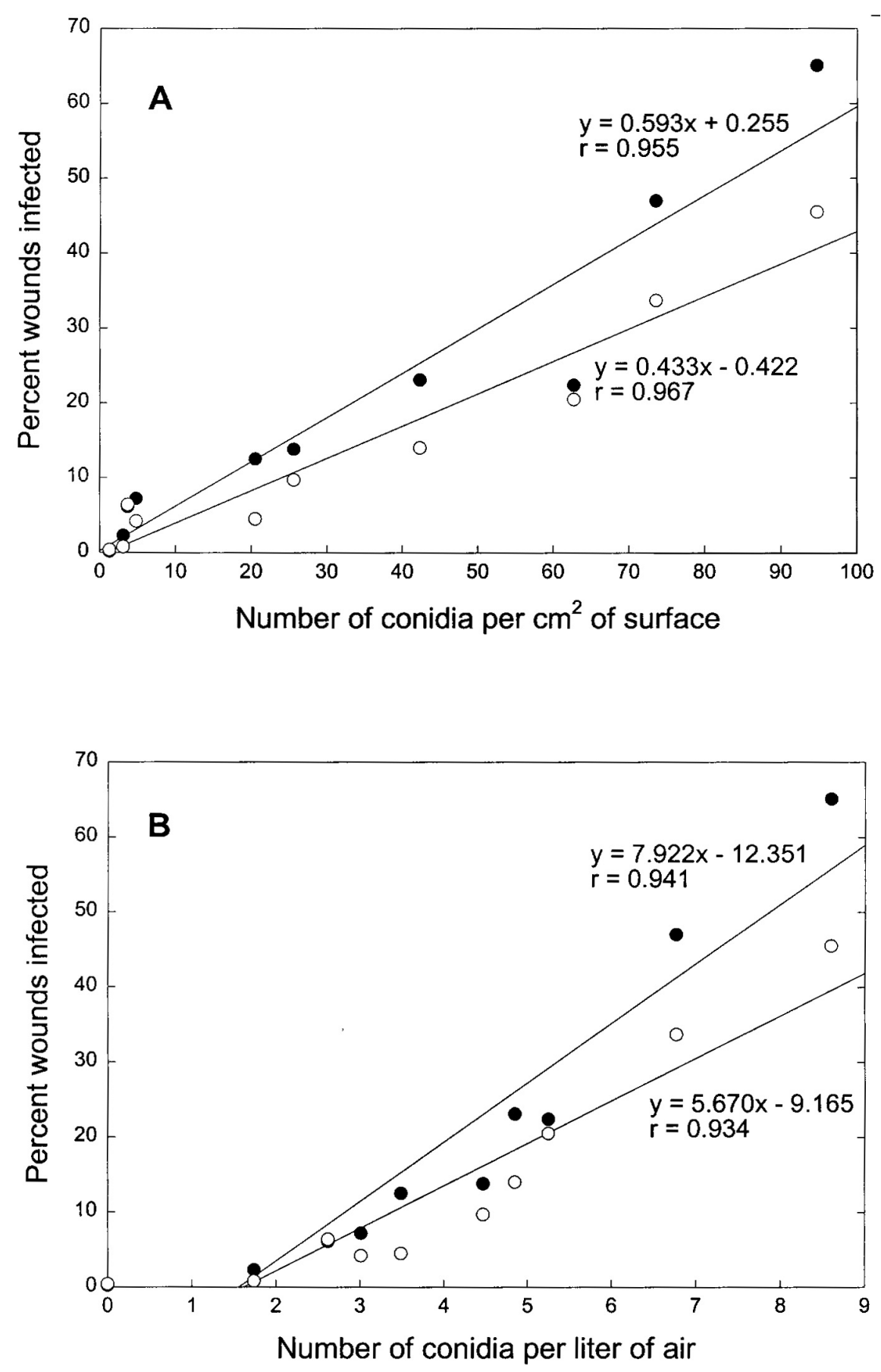

Fig. 2. Relationship between incidence of gray mold of d'Anjou pear fruit and inoculum dose of Botrytis cinerea expressed as $\mathbf{A}$, conidia per $\mathrm{cm}^{2}$ and $\mathbf{B}$, number of conidia per liter of air. Fruit were dry when inoculated. Solid and open circles represent data points for fruit wounded before and after inoculation, respectively. 
juice in and around the wound, possibly creating conditions favorable for hydration of conidia and may increase the opportunity for adhesion and infection by $B$. cinerea.

Decay was greater for $B$. cinerea, but not $P$. expansum, when fruit were inoculated while wet and immediately placed in storage than when fruit were dry. During harvest in late August and September, morning dew is common in Mid-Columbia area orchards (18). In addition, rain is not uncommon during pear harvest. Thus, wet as well as dry fruit are often harvested. Increased decay of wet fruit by $B$. cinerea may be related to increased adhesion of conidia as noted above. While germination of conidia of $B$. cinerea begins in less than $2 \mathrm{~h}$ (19), $P$. expansum conidia germinate more slowly. At $20^{\circ} \mathrm{C}$, less than $47 \%$ of $P$. expansum conidia germinated after $16 \mathrm{~h}$ (2). Increased decay of pear fruit caused by Mucor piriformis has been associated with harvesting wet fruit (1). Sporangiospores of $M$. piriformis germinate at a rate similar to conidia of $B$. cinerea (2).
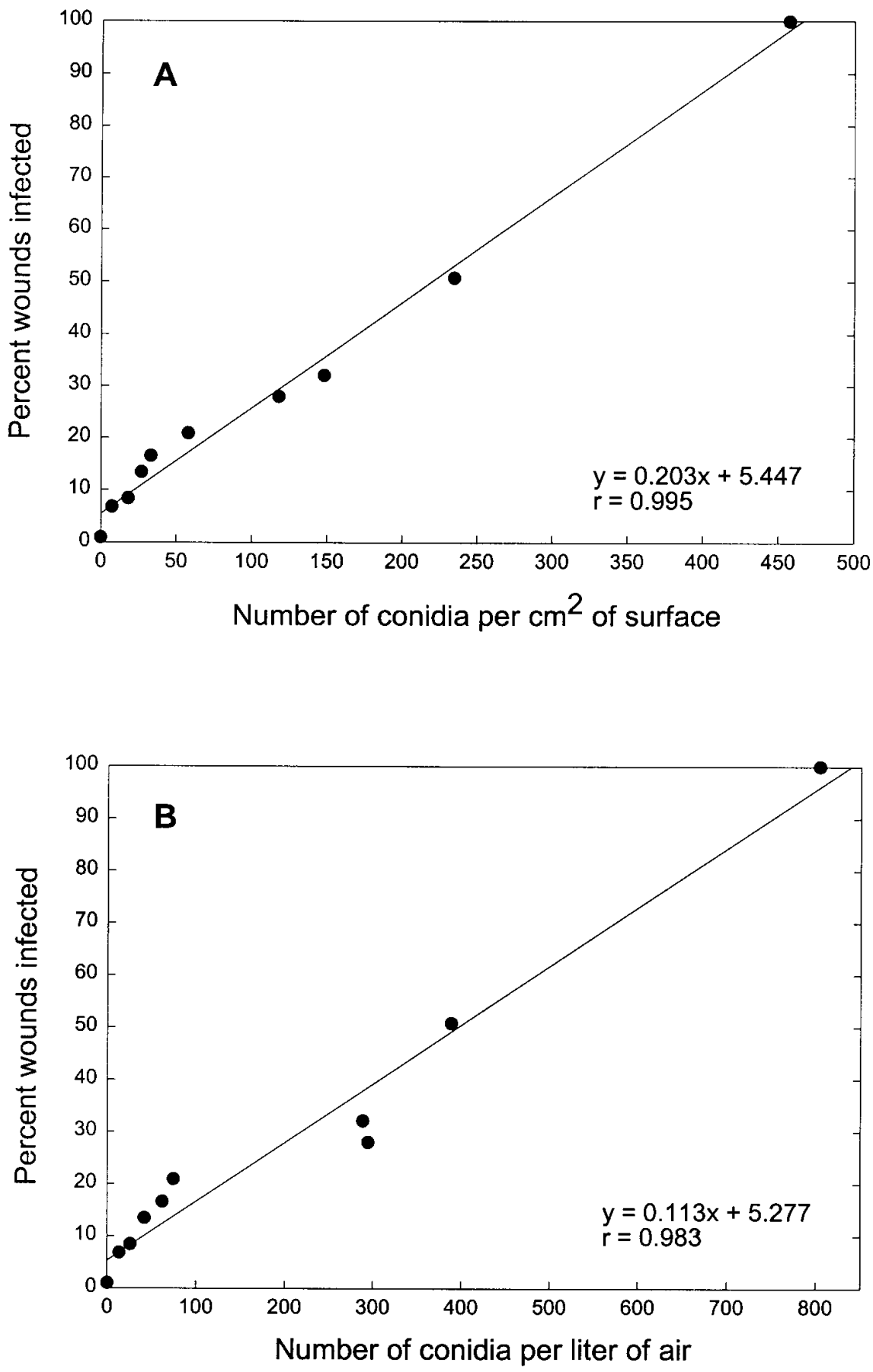

Fig. 3. Relationship between incidence of blue mold of d'Anjou pear fruit and inoculum dose of Penicillium expansum expressed as $\mathbf{A}$, conidia per $\mathrm{cm}^{2}$ and $\mathbf{B}$, number of conidia per liter of air. Data were combined for wet and dry fruit wounded before and after inoculation.
Research is continuing on concentrations of conidia of $B$. cinerea and $P$. expansum in air, soil, litter, and on fruit surfaces in orchards and packinghouses in the MidColumbia area. Because all regressions of decay incidence versus airborne and surface conidial concentrations were highly significant, it is possible that DI:ID relationships derived in this study may be useful for predicting risks of fruit decay from measurements of conidia concentrations of $B$. cinerea and $P$. expansum in orchard and packinghouse environments. However, conditions in the field include many variables not encountered under the controlled conditions used herein. Because the stem abscission area is an important infection court during harvest and storage of pear fruit (15), studies also are underway to develop DI:ID relationships when the abscission area of pear fruit stems is inoculated with dry conidia.

\section{ACKNOWLEDGMENTS}

We thank the Winter Pear Control Committee for partial funding of the research, and Helen Cahn for statistical advice. Use of trade names in this article does not imply endorsement by Oregon State University of the products named or criticism of similar products not mentioned. Oregon Agricultural Experiment Station technical paper 11726.

\section{LITERATURE CITED}

1. Bertrand, P., and Saulie-Carter, J. 1980. Mucor rot of pears and apples. Agric. Exp. Sta. Oregon State Univ. Spec. Rep. 568.

2. Boonyakiat, D., Spotts, R. A., and Richardson, D. G. 1986. Effects of chlorogenic acid and arbutin on growth and spore germination of decay fungi. HortScience 21:309-310.

3. Borecka, H. 1977. Fungi of the genus Penicillium on apples and pears during the storage period. Acta Agrobotanica 30:213-227.

4. Chen, P. M., Spotts, R. A., and Mellenthin, W. M. 1981. Stem-end decay and quality of low oxygen stored d'Anjou pears. J. Am. Soc. Hortic. Sci. 106:695-698.

5. Coertze, S., and Holz, G. 1999. Surface colonization, penetration, and lesion formation on grapes inoculated fresh or after cold storage with single airborne conidia of Botrytis cinerea. Plant Dis. 83:917-924.

6. Domsch, K. H., Gams, W., and Anderson, T.-H. 1980. Compendium of soil fungi, Vol. 1. Academic Press, London.

7. Doss, R. P., Potter, S. W., Chastagner, G. A., and Christian, J. K. 1993. Adhesion of nongerminated Botrytis cinerea conidia to several substrates. Appl. Environ. Microbiol. 59:1786-1791.

8. Jarvis, W. R. 1962. The dispersal of spores of Botrytis cinerea in a raspberry plantation. Trans. Br. Mycol. Soc. 45:549-559.

9. Jarvis, W. R. 1980. Epidemiology. Pages 219250 in: The Biology of Botrytis. J. R. ClaySmith, K. Verhoff, and W. R. Jarvis, eds. Academic Press, London.

10. Miller, P. M., and Waggoner, P. E. 1957. Dispersal of spores of Botrytis cinerea among strawberries. (Abstr.) Phytopathology 47:24-25.

11. Pierson, C. F., Ceponis, M. J., and McColloch, L. P. 1971. Market diseases of apples, pears, and quinces. Agric. Handbook 376, U.S. Dept. Agric., Washington, D.C.

12. Salinas, J., Glandorf, D. C. M., Picavet, F. D., and Verhoeff, K. 1989. Effects of temperature, relative humidity, and age of conidia in the incidence of spotting on gerbera flowers caused by Botrytis cinerea. Neth. J. Plant Pathol. 
95:51-64.

13. Sanderson, P. G., and R. A. Spotts. 1995. Postharvest decay of winter pear and apple fruit caused by species of Penicillium. Phytopathology 85:103-110.

14. Spotts, R. A. 1985. Effect of preharvest pear fruit maturity on decay resistance. Plant Dis. 69:388-390.

15. Spotts, R. A. 1986. Relationships between inoculum concentration of three decay fungi and pear fruit decay. Plant Dis. 70:386-389.
16. Spotts, R. A. and Cervantes, L. A. 1986. Populations, pathogenicity, and benomyl resistance of Botrytis spp., Penicillium spp., and Mucor piriformis in packinghouses. Plant Dis. 70:106108.

17. Spotts, R. A., and Cervantes, L. A. 1994. Contamination of harvest bins with pear decay fungi and evaluation of disinfestants on plastic and wood bin material. Acta Horticulturae 367:419-425.

18. Spotts, R. A., and L. A. Cervantes. 1994. Fac- tors affecting maturation and release of ascospores of Venturia pirina in Oregon. Phytopathology 84:260-264.

19. Spotts, R. A., and Holz, G. 1996. Adhesion and removal of conidia of Botrytis cinerea and Penicillium expansum from grape and plum fruit surfaces. Plant Dis. 80:688-691.

20. Spotts, R. A., Sanderson, P. G., Lennox, C. L., Sugar, D., and Cervantes, L. A. 1998. Wounding, wound healing and staining of mature pear fruit. Postharvest Biol. Technol. 13:27-36. 